\title{
PROF. DR. DR. H.C. MULT. MICHAEL MÜLLER-WILLE - SZKIC DO PORTRETU BADAWCZEGO
}

Prof. Dr. Dr. h.c. mult. Michael Müller-Wille urodził się 1 marca 1938 r. w westfalskim Münster. Tu ukończył w roku 1958 liceum Paulinum i rozpoczął studia prehistoryczne oraz z archeologii klasycznej i geografii na Westfälische Wilhelms-Universität Münster. Studiował także prehistorię Skandynawii i geologię czwartorzędu na Uniwersytecie w Uppsali. Był również studentem Uniwersytetu w Montpellier. W 1964 doktoryzował się na uniwersytecie w Münster. W latach 1964-1965 pracował w Rheinisches Landesmuseum Bonn. Od roku 1965 związał się z Christian-Albrechts-Universität zu Kiel, gdzie do roku 1976 był asystentem i wykładowcą. W 1970 r. habilitował się na Uniwersytecie Johannesa Gutenberga w Moguncji, gdzie od 1976 do 1981 był profesorem zwyczajnym w Institut für Vor- und Frühgeschichte, pełnił też tam funkcję Dziekana Wydziału Historii i Kulturoznawstwa (Dekan des Fachbereichs Geschichts- und Kulturwissenschaften), był również Vertrauensdozent Studienstiftung des Deutschen Volkes. W roku 1981 powrócił do Kilonii na Uniwersytet Christiana-Albrechta do Institut für Ur- und Frühgeschichte. W latach 1986-1987 pełnił funkcję Dziekana Wydziału Filozoficznego (Dekan der Philosophischen Fakultät), by w latach 1989-1991 zostać Rektorem Uniwersytetu w Kilonii. Do przejścia na emeryturę w roku 2003 zatrudniony był jako profesor zwyczajny w swoim macierzystym Instytucie.

W zainteresowaniach badawczych już od początków kariery naukowej Michaela Müller-Wille dominowała fascynacja archeologią osadniczą. Jeszcze w czasach studenckich zainteresował się możliwościami archeologicznego śledzenia form użytkowania gruntów uprawnych zarówno dla czasów pradziejowych, jak i wieków średnich. Zagadnieniu temu poświęcił swoją dysertację doktorską, w której zaprezentował pionierskie, z punktu widzenia metodyki ówczesnej archeologii, rozważania dotyczące identyfikacji pól uprawnych w epoce żelaza, na terenach południowego pobrzeża wschodniej części basenu Morza Północnego (Müller-Wille

* ORCID 0000-0003-1778-9725; Wydział Archeologii UAM, ul. Uniwersytetu Poznańskiego 7, 61-614 Poznań, e-mail: misiek@amu.edu.pl. 
1965; 1968). Dalsze studia prowadzone przezeń nad zagadnieniem możliwości poznania krajobrazu osadniczego to niewątpliwie próba odtworzenia historii osadnictwa wschodniego Szlezwiku i wybrzeża północnofryzyjskiego, poczynając od epoki brązu, a na wczesnym średniowieczu kończąc (np. Müller-Wille 1977a; 1979; 1984a; 1984b; Müller-Wille, Higelke, Hoffmann i Petersen 1976; Müller-Wille, Higelke, Hoffmann i Kühn 1979; Müller-Wille i Voss 1973). Te studia wpłynęły na rozwinięcie przez prof. Michaela Müller-Wille niezwykle interesującego i nowatorskiego nurtu badawczego, mającego za zadanie odtworzenie dziejów strefy obszarów wybrzeży morskich.

Z nurtu studiów osadniczych wyrastają także zainteresowania prof. Michaela Müller-Wille dziejami wczesnośredniowiecznej Europy Środkowej, w tym w szczególny sposób również ówczesnej Słowiańszczyzny. Kamieniem milowym dla tych rozważań stały się badania grodu w Stargardzie Wagryjskim (Oldenburg im Wagrien) i jego zaplecza osadniczego. Gród rozwinął się tam między rokiem 780 a 840. Jego zasięg w końcu VIII w. poszerzony został ku wschodowi, by zrobić miejsce dla rezydencji książąt panujących nad słowiańskim plemieniem Wagrów. Od południa natomiast badania potwierdziły rozwój otwartego podgrodzia. Prace o charakterze interdyscyplinarnym prowadzone były przez Michaela Müller-Wille w kontekście szeroko pojętych studiów nad tłem środowiskowym, $\mathrm{w}$ tym próby uchwycenia zachodzącej w nim antropopresji. W tym nurcie badań rozwijały się też te, które związane były z poznaniem problematyki ośrodków wczesnomiejskich w basenie Morza Bałtyckiego (np. Müller-Wille 1977b; 1988; 1991; 1998a).

Drugi niezwykle ważny nurt w zainteresowaniach naukowych prof. Michaela Müller-Wille łączył się z zagadnieniami tyczącymi zachowań funeralnych społeczności basenu Morza Północnego i Bałtyckiego. Tę problematykę uczynił on tematem swojej rozprawy habilitacyjnej (Müller-Wille 1969). Ustalenia poczynione $\mathrm{w}$ tejże rozprawie były efektem studiów nad niezwykle interesującym zjawiskiem, jakim były groby w łodziach. Wykorzystanie w celach sepulkralnych jednostek pływających nie należało we wczesnym średniowieczu do rzadkości w basenie Morza Bałtyckiego i chociaż zwyczaj ten rozpowszechniony był głównie wśród Skandynawów, widzimy je również na terenach słowiańskich i bałtyjskich. Ówczesne studia prof. Müller-Wille wniosły znaczący wkład w tę tematykę, jego praca zaś do dzisiaj jest powszechnie cytowana przez badaczy zajmujących się obrządkiem pogrzebowym społeczności wczesnośredniowiecznej Europy. Dzieło to stało się inspiracją do dalszych studiów tegoż badacza nad kwestiami wynikającymi z obserwacji poruszanej weń problematyki. Kwestie grobów w łodziach stały się inspiracją do powstania dalszych jego prac, poświęconych temu zagadnieniu (m.in. Müller-Wille 1974; 1976a; 1978a; 2002 2007). Równolegle zajął się także innymi aspektami, wynikającymi z bogatej problematyki średniowiecznych grobów elitarnych, które analizował w swych kolejnych, licznych tekstach (zob. np. Müller-Wille 1978b; 1985; 1997; 2006). Stworzyły one podstawy do głębszych analiz 
w prezentacji elit ówczesnych społeczeństw (Müller-Wille 1996). Ostatnimi laty jego ogromne zainteresowanie wzbudziło polskie odkrycie cmentarzyska elitarnego o cechach skandynawskich, dokonane na stanowisku w Bodzi, położonym na Kujawach. Jego studia poświecone materiałom z tegoż stanowiska wniosły dla wiedzy o tym fascynującym odkryciu niezwykle znaczący wkład (Müller-Wille 2014; 2015; 2016).

Profesor Michael Müller-Wille był doskonałym źródłoznawcą. W jego piśmiennictwie liczne są przykłady tekstów, gdzie opracowuje pojedyncze przedmioty, z wielkim znawstwem kreśląc ich charakterystykę na szerokim tle porównawczym. Również w szerokim kontekście dokonywał pełnych opracowań stanowisk zarówno funeralnych, jak chociażby cmentarzyska w Thumby-Bienebek (Müller-Wille 1976b), jak i wspominanych już wcześniej osad.

Osobnym przedmiotem zainteresowania prof. M. Müller-Wille było religioznawstwo. Tu również, opierając się na swoich doświadczeniach wynikających ze studiów nad obrządkiem pogrzebowym i systemem społecznym wczesnośredniowiecznej Europy, potrafił przedstawić niezwykle erudycyjny obraz zmian zachodzących w wierzeniach ówczesnych społeczności, ich przejawach czytelnych w odpowiadającej im kulturze materialnej, związanych z rozprzestrzenianiem się chrześcijaństwa wśród plemion germańskich (np. Müller-Wille 1994; 1998b; 1998c). Z tym zagadnieniem wiąże się także kwestia poruszanego w piśmiennictwie Profesora problemu badań pogańskich miejsc ofiarnych (Müller-Wille 1984c; 1989c).

Prof. Dr. Dr. h.c. mult. Michael Müller-Wille był członkiem licznych komisji Deutsches Archäologisches Institut w Bonn, w tym Römisch-Germanische Kommission des Deutschen Archäologischen Institutes; Eurasien-Abteilung Berlin; Kommission für Allgemeine und Vergleichende Archäologie, Förderkommission Ostpartnerschaften.

Był także członkiem licznych rad muzealnych oraz instytucji badawczych w Niemczech oraz w Europie, w tym między innymi: Geisteswissenschaftliches Zentrum Geschichte und Kultur Ostmitteleuropas (GWZO) Leipzig; Deutsches Schifffahrtsmuseum Bremerhaven; Centre of Maritime Archaeology Roskilde, Institut für Landesforschung der Christian-Albrechts-Universität zu Kiel, Forschungsund Technologiezentrum (FTZ) Büsum, Stiftungsrat Stiftung Schleswig-Holsteinische Landesmuseen Schloss Gottorf, Societé Royale des Lettres de Lund; Vetenskapssocieteten i Lund; Joachim Jungius-Gesellschaft der Wissenschaften Hamburg; Akademie der Wissenschaften und der Literatur Mainz; Kungl. Vitterhets Historie och Antikvitets Akademien Stockholm; Koninklijke Nederlandse Akademie van Wetenschappen.

Wieloletni recenzent projektów eksperckich i komitetu długoterminowego w Deutsche Forschungsgemeinschaft.

Za swoją działalność, jaką prowadził na rzecz rozwoju nauki, nagradzany był licznymi odznaczeniami, takimi jak: Złoty Medal Łomonosowa Rosyjskiej Akademii Nauk (1999), Alexander von Humboldt Foundation Honorary Research 
Fellowship Polen (2004), Königlich Schwedischer Nordsternorden (2004). Uzyskał także zaszczytne tytuły Doktora honoris causa uniwersytetów w Umeå (1989), Poznaniu (1993) i Yorku (2001).

Trudno jest $\mathrm{w}$ tak krótkim tekście pomieścić tak wybitną postać. Chcąc to zrobić, można stworzyć wówczas tylko pewien drobny szkic - szkic, stanowiący jedynie zaznaczenie tych najważniejszych dokonań Prof. Dr. Dr. h.c. mult. Michaela Müller-Wille. Szkic, który zasadniczo dotyka zaledwie tych niezliczonych aspektów życia naukowego i akademickiego, którymi badacz ów się zajmował. Doskonały organizator, administrator, ale przede wszystkim wielki uczony, którego największą pasją naukową była zawsze archeologia. Ta wczesnego średniowiecza zdominowała niewątpliwie piśmiennictwo prof. Michaela Müller-Wille. Znacząca większość jego tekstów była poświecona temu właśnie okresowi. Oczywiście, jak na takiego erudytę przystało, pojawiały się w trakcie jego przebogatej kariery naukowej także prace tyczące wcześniejszych epok, od neolitu, przez brąz po czasy historyczne. W tym nurcie dominowały przede wszystkim te, które dotyczyły schyłku wpływów rzymskich i doskonale znanego mu okresu wędrówek ludów.

Niemniej najznamienitszy wkład wniósł on w prezentację styku światów germańskiego i słowiańskiego. I to nie tylko w kontekście swych myśli przelanych w setki stron tekstów, ale także licznych projektów badawczych, konferencji i innych realnych spotkań z uczonymi z tych krajów, których sięgały jego prace naukowe. Jego kontakty, jeszcze w dobie ,żelaznej kurtyny” dawały ogromną szansę rozwoju badań naukowych po obu jej stronach, którym z wielkim zaangażowaniem patronował. Prof. Dr. Dr. h.c. mult. Michael Müller-Wille był bowiem wielkim przyjacielem słowiańskiej archeologii. W tym poczesne miejsce zajmowali w jego sercu polscy, a w szczególny wręcz sposób poznańscy archeolodzy. Wspierał on swym autorytetem ideę wspólnych badań i wymiany pracowników między ośrodkami archeologicznymi w Poznaniu i Kilonii, w której także sam brał aktywny udział. W semestrze letnim roku akademickiego 1983/1984 prowadził w Instytucie Prahistorii UAM cykl wykładów na temat badań najstarszych ośrodków miejskich powstających w strefie Bałtyku i Morza Północnego oraz poświęconych zagadnieniu wymiany handlowej w najstarszych fazach wczesnego średniowiecza.

Będąc już na emeryturze, nadal współpracował z poznańskim ośrodkiem archeologicznym, publikując swoje teksty w roczniku „Slavia Antiqua” (Müller-Wille 2009) oraz monografiach zbiorowych (Müller-Wille 2015). Zawsze serdeczny i gościnny, chętnie wspierał swą ogromną wiedzą naukową poznańskich stypendystów odwiedzających Institut für Vor- und Frühgeschichte CAU.

Odszedł od nas w dniu 14 listopada 2019 w swojej ukochanej Kilonii, z którą związał swe najlepsze lata kariery zawodowej i życia rodzinnego. Pustkę po odejściu tak wybitnego Uczonego będzie niezwykle trudno wypełnić, jednak jego spuścizna naukowa powoduje, iż tak naprawdę jest cały czas wśród nas. Jego myśl nie zagasła i nigdy nie zgaśnie - płonąć będzie jasnym światłem we wszystkich pracach, które przywołają dzieła tego Wybitnego Badacza, tak jak latarnia morska 
- wskazując podążającym za nim nowym pokoleniem coraz to inne porty, do których jemu samemu nie było dane już dotrzeć.

\section{Cześć Jego pamięci!}

\section{BIBLIOGRAFIA}

Müller-Wille M. 1965, Eisenzeitliche Fluren in den festländischen Nordseegebieten. Landeskundliche Karten und Hefte der Geographischen Kommission fur Westfalen, Siedlung und Landschaft in Westfalen 5, Münster.

- 1968, Vor-und frühgeschichtliche Ackerfluren in Schleswig-Holstein, w: Führer zu vor-und Frühgeschichtlichen Denkmälern, Band 9, Schleswig-Haithabu-Sylt, Mainz, s. 70-76.

- 1969, Bestattung im Boot. Studien zu einer nordeuropäischen Grabsitte, „Offa“ 25/26, 1968/69, s. $5-203$

- 1974, Boatgraves in Northern Europe, "The International Journal of Nautical Archaeology and Underwater Exploration" 3 (2), s. 187-204.

- 1976a, Das Bootkammergrab von Haithabu, Mit Beiträgen von O. Crumlin-Pedersen und M. Dekówna. Berichte über die Ausgrabungen in Haithabu 8, Neumünster.

- 1976b, Das wikingerzeitliche Gräberfeld von Thumby-Bienebek (Kr. Rendsburg-Eckernförde), Teil 1, „Offa-Bücher” 36, Neumünster.

- 1977a, Bäuerliche Siedlungen der Bronze-und Eisenzeit in den Nordseegebieten, w: H. Jankuhn, R. Schützeichel und F. Schwind (Hrsg.), Das Dorf der Eisenzeit und des frühen Mittelalters. Abhandlungen der Akademie der Wissenschaften Göttingen, Philologisch-Historische Klasse, Dritte Folge Nr. 101, Göttingen, s. 153-218.

- 1977b, Hedeby, "Nautical Archaeology“ 6, s. 168.

- 1978a, Das Schiffsgrab von der Ile de Groix (Bretagne). Ein Exkurs zum „Bootkammergrab von Haithabu“, Berichte über die Ausgrabungen in Haithabu 12, Neumünster, s. 48-84.

- 1978b, Frühmittelalterliche Prunkgräber im südlichen Skandinavien. Bonner Jahrbücher 178, 1978, s. 633-652.

- 1979, Flursysteme der Bronze-und Eisenzeit in den Nordseegebieten. Zum Stand der Forschung über „, celtic fields“, w: H. Beck, D. Denecke und H. Jankuhn (red.), Untersuchungen zur eisenzeitlichen und frühmittelalterlichen Flur in Mitteleuropa und ihrer Nutzung, Teil 1 [Kongreß Göttingen 1975 und 1976], Abhandlungen der Akademie der Wissenschaften in Göttingen, Philologisch-Historische Klasse, Dritte Folge Nr. 115, Göttingen, s. 196-239.

- 1984a, Mittelalterliche und frühneuzeitliche Siedlungsentwicklung in Moor-und Marschengebieten. Siedlungsforschung, „Archäologie - Geschichte - Geographie“ 2, 1984, s. 7-41.

- 1984b, Mittelalterliche und frühneuzeitliche Siedlungsentwicklung in Moor-und Marschengebieten, Tagungsbericht, Ebenda, s. 245-258.

- 1984c, Opferplätze der Wikingerzeit, „Frühmittelalterliche Studien“ 18, s. 187-221.

- 1985, Frühmittelalterliche Bestattungen in Wagen und Wagenkästen, „Archaeology and Environment" 4, Umeå, s. 17-30.

- 1988, Hedeby und sein Umland. Archäologische Zeugnisse des Handels, w: B. Hårdh i in. (red.), Trade and Exchange in Prehistory. Studies in Honour of Berta Stjernquist, Acta Archaeologica Lundensia Series in $8^{\circ}$. $\mathrm{N}^{\circ}$. 16, Lund, s. 271-278.

- 1989, Heidnische Opferplätze im frühgeschichtlichen Europa nördlich der Alpen. Die archäologische Überlieferung und ihre Deutung. Sitzungsberichte Joachim Jungius-Gesellschaft 7, Heft 3, Hamburg.

- 1991, Frühstädtische Siedlungen und ihr Umland. Beispiele Haithabu und Ribe, w: H. Brachmann und J. Herrmann (red.), Frühgeschichte der europäischen Stadt. Voraussetzungen und Grundlagen. Zentralinstitut fur Alte Geschichte und Archäologie Berlin. Schriften zur Ur- und Frühgeschichte 44, Berlin, s. 226-236. 
- 1994, From Paganism to Christlanity: A Regional Study - the South West Baltic, w: M. Rindal (red.), Three Studies on Vikings and Christianization. The Research Council of Norway, KULTs skriftserie No. 28, Religionsskiftet No. 1 (Oslo 1994), s. 44-73.

- 1996, Königtum und Adel im Spiegel der Grabfunde, w: A. Wieczorek, P. Périn, K. von Welck und W. Menghin (red.), Die Franken - Wegbereiter Europas, Vor 1500 Jahren: König Chlodwig und seine Erben, Mainz, s. 206-221.

- 1997, Les tombes royales à tumuli, "Dossier d" Archéologie“ 223, s. 32-37.

- 1998a, Starigard/Oldenburg - Wolin - Novgorod. Besiedlung und Siedlungen im Umland slawischer Herrschaftszentren. Ein fachübergreifendes Forschungsprojekt, w: Ch. Lübke (red.), Struktur und Wandel im Früh-und Hochmittelalter. Eine Bestandsaufnahme aktueller Forschungen zur Germania Slavica. Geisteswissenschaftliches Zentrum Geschichte und Kultur Ostmitteleuropas e.V. Forschungen zur Geschichte und Kultur des östlichen Mitteleuropa 5, Stuttgart, s. 187-198.

- 1998b, Zwei religiöse Welten: Bestattungen der fränkischen Könige Childerich und Chlodwig. Akademie der Wissenschaften und der Literatur Mainz. Abhandlungen der Geistes-und Sozialwissenschaftlichen Klasse, Jahrgang 1998, Heft 1, Stuttgart 1998.

- 1998c, The Cross as a Symbol of Personal Christian Belief in a Changing Religious World. Examples from Selected Areas in Merovingian and Carolingian Europe, w: L. Larsson und B. Stjernquist (red.), The World-View of Prehistoric Man. Papers presented at a Symposium in Lund, 5-7 may 1997, arranged by the Royal Academy of Letters, History and Antiquities along with the Foundation Natur och Kultur. Kungl. Vitterhets Historie och Antikvitets Akademien. Konferenser 40, Stockholm, s. 179-200.

- 2002, Das Bootgrab von Balladoole, Isle of Man. Deutsches Schiffahrtsarchiv 25, s. 295-310.

- 2006, Prunkgräber der Völkerwanderungs-und Merowingerzeit, w: C. von Carnap-Bornheim, D. Krausse und A. Wesse (red.), Herrschaft-Tod-Bestattung. Zu den vor-und frühgeschichtlichen Prunkgräbern als archäologisch-historische Quelle, Universitätsforschungen zur Prähistorischen Archäologie 135, Bonn, s. 17-145.

- 2007, Four Viking Age boat burials in comparison. Gausel - Scar - Kiloran Bay - Balladoole, w: B. Hårdh, K. Jennbert und D. Olausson (red.), On the road. Studies in honour of Lars Larsson. Acta Archaeologica Lundensia in $4^{\circ} \mathrm{N}^{\circ}$. 26, Stockholm, s. 287-294.

- 2009, Schmuckgut aus spätslawischen Fürstenburgen und Grablegen des obodritischen Herrschaftsgebietes, „Slavia Antiqua” 50, s. 299-318.

- 2014, The Cemetery at Bodzia in a Broader European Context, w: A. Buko (red.), Bodzia. A Late Viking-Age Elite Cemetery in Central Poland. East Central and Eastern Europe in the Middle Ages, 450-1450, vol. 27, Leiden-Boston, s. 479-510.

- 2015, Das Schwertgrab E864/I aus dem frühen 11. Jahrhundert von Bodzia, Kujawien, w: A. Michałowski, M. Teska, M. Żółkiewski (red.), Viator per devia scientiae itinera. Studia nad problematyka okresów przedrzymskiego, rzymskiego, wędrówek ludów i wczesnego średniowiecza, Poznań, s. 327-337.

- 2016, Cmentarzysko w Bodzi w kontekście odkryć w pótnocno-zachodniej i wschodniej Europie, w: A. Buko (red.), Bodzia. Elitarny cmentarz z początków państwa polskiego, Warszawa, s. 459-479.

Müller-Wille M., Higelke B., Hoffmann D., Kühn J. 1979, Geowissenschaftlich-archäologische Untersuchungen zur Landschafts- und Siedlungsgeschichte von Nordfriesland, „Archäologisches Korrespondenzblatt" 9, s. 223-239.

Müller-Wille M, Higelke B., Hoffmann D., Petersen M. 1976, Landschaftsentwicklung und Siedlungsgeschichte der nordfriesischen Marscheninseln und Watten im Einzugsbereich der Norderhever, „Probleme der Küstenforschung im sudlichen Nordseegebiet" 11, s. 163-185.

Müller-Wille M., Voss F. 1973, Geomorphologische und archäologische Untersuchungen im Mündungsgebiet der Langballigau an der Flensburger Förde, „Ebenda“, s. 123-127. 